\title{
Assessing the impact of the Kuroshio Current on vertical cloud structure using CloudSat data
}

\author{
Akira Yamauchi ${ }^{1}$, Kazuaki Kawamoto ${ }^{1}$, Atsuyoshi Manda ${ }^{1,2}$, and Jiming $\mathbf{L i}^{3}$ \\ ${ }^{1}$ School of Fisheries Science and Environmental Sciences, Nagasaki University, Nagasaki, Japan \\ ${ }^{2}$ Earth and Environmental Sciences Division, Graduate School of Bioresources, Mie University, Mie, Japan \\ ${ }^{3}$ Key Laboratory for Semi-Arid Climate Change of the Ministry of Education, College of Atmospheric Sciences, \\ Lanzhou University, Lanzhou, China
}

Correspondence: Akira Yamauchi (akira19890620@gmail.com)

Received: 6 December 2017 - Discussion started: 12 January 2018

Revised: 26 April 2018 - Accepted: 8 May 2018 - Published: 1 June 2018

\begin{abstract}
This study analyzed CloudSat satellite data to determine how the warm ocean Kuroshio Current affects the vertical structure of clouds. Rainfall intensity around the middle troposphere $(6 \mathrm{~km}$ in height $)$ over the Kuroshio was greater than that over surrounding areas. The drizzle clouds over the Kuroshio have a higher frequency of occurrence of geometrically thin $(0.5-3 \mathrm{~km})$ clouds and thicker $(7-10 \mathrm{~km})$ clouds compared to those around the Kuroshio. Moreover, the frequency of occurrence of precipitating clouds with a geometric thickness of 7 to $10 \mathrm{~km}$ increased over the Kuroshio. Stronger updrafts over the Kuroshio maintain large droplets higher in the upper part of the cloud layer, and the maximum radar reflectivity within a cloud layer in non-precipitating and drizzle clouds over the Kuroshio is higher than that around the Kuroshio.
\end{abstract}

\section{Introduction}

Clouds are recognized as one of the primary sources of uncertainty in understanding and predicting global climate change (e.g., Stephens, 2005; Dufresne and Bony, 2008). As a key component of the climate system, clouds have a significant influence on hydrological cycles and energy budgets. Cloud effects are strongly regulated by their microphysical (particle size, number concentration, and mass density of water or ice particulates) and macro-physical (temporal frequency, height, geometrical thickness, and rainfall intensity) structure; thus, an investigation of the internal structure of clouds provides insight into various atmospheric phenomena.
For example, Kawamoto and Hayasaka (2008) reported that the surface radiative properties were crucially regulated by cloud optical thickness (COT) and cloud cover. However, the general circulation models (GCMs) underestimated (overestimated) the cloud fraction (the radiative effect) in tropical low-level clouds (Nam et al., 2012) - so-called "too few, too bright" problem. Moreover, Suzuki et al. (2015) reported that the warm cloud auto-conversion process in the GCMs was too rapid compared to that derived from satellite observation. It is necessary to understand the vertical structure of clouds to reduce the cloud bias in the GCMs.

The advent of active remote-sensing data has provided a more detailed picture of some cloud effects. CloudSat is a part of a satellite constellation of passive and active sensors called the A-train, which crosses the equator within a few minutes of one another at about 13:30 LT from a $705 \mathrm{~km}$ altitude orbit (Stephens et al., 2002). CloudSat carries a cloudprofiling radar (CPR) that operates at $94 \mathrm{GHz}$. The CloudSat CPR is sensitive to large cloud particles and hydrometeors (Haynes et al., 2009). Huang et al. (2016) reported that liquid-phase cloud properties (cloud top temperature, effective radius, cloud optical thickness, and liquid water path) of the Southern Ocean strongly correlate with the sea surface temperature (SST) using A-train satellite observations. In this study, we clarified how the vertical structure (rainfall intensity, cloud geometrical thickness, and maximum radar reflectivity position) was affected by strong upward wind flow over the Kuroshio Current. The Kuroshio, a western boundary current of the North Pacific Subtropical Gyre, flows northward along the east coast of Taiwan into the East 
China Sea (ECS). This current carries warm water from the tropics and forms a warm tongue in the SST field in the ECS. The recent studies indicate the influence of the Kuroshio SST on the atmosphere of the ECS is as strong as other western boundary currents such as the Gulf Stream and Agulhas Current (e.g., Xie et al., 2004; Small et al., 2008). Evaporation from the sea surface in the Kuroshio region enhances the formation of convectively unstable air masses, which can produce deep convection (Kuwano-Yoshida, 2013; Tsuguti and Kato, 2014; Manda et al., 2014; Kunoki et al., 2015; Sato et al., 2016). The Kuroshio also impacts the surface wind convergence, which in turn helps form the deep convective clouds (Xu et al., 2011; Sasaki et al., 2012; Miyama et al., 2012). Recent studies reported the impact of the Kuroshio on the cloud vertical structure. Liu et al. (2016) reported the low cloud response to the Kuroshio from winter to spring. However, our understanding of the impact of the Kuroshio on the vertical structure and hydrometeor over the Kuroshio is still limited. In this study, we investigate how the sea surface temperature changes around the Kuroshio affect the vertical structure and hydrometeor of clouds during early summer.

This paper is organized as follows. In Sect. 2, we showed the data, target region, and method. In Sect. 3.1, we described the influence of the Kuroshio on atmospheric conditions. In Sect. 3.2, we presented the relationship between radar reflectivity and altitude. The relationship between geometrically thick clouds and rainfall intensity was discussed in Sect. 3.3. Finally, in Sect. 3.4, we described the maximum radar reflectivity position inside clouds. In Sect. 4, we summarized our overall conclusions.

\section{Data and methods}

The CloudSat footprint is approximately $1.7 \mathrm{~km}$ along-track by $1.4 \mathrm{~km}$ across-track. One granule consists of approximately 36383 profiles, and one profile has 125 vertical bins, each of which is $240 \mathrm{~m}$ thick. In this study, we used the CloudSat product 2B-GEOPROF $240 \mathrm{~m}$ resolution vertical distribution of the cloud mask, radar reflectivity (Mace et al., 2007; Marchand et al., 2008), altitude, and temperature profiles from the European Center for Medium-Range Weather Forecasts (ECMWF-AUX; Partain, 2007); precipitating liquid and ice water content (PLWC and PIWC) from 2C-RAIN-PROFILE (Mitrescu et al., 2010; Lebsock et al., 2011); heating rates from 2B-FLXHR (L'Ecuyer et al., 2008); cloud droplet effective radius $\left(r_{\mathrm{e}}\right)$ and cloud optical thickness $(\tau)$ from Aqua/Moderate Resolution Imaging Spectroradiometer (MODIS); precipitating rate from the Tropical Rainfall Measuring Mission (TRMM) Multisatellite Precipitation Analysis (TMPA, $0.25^{\circ} \times 0.25^{\circ}$; Huffman, 1997; Huffman et al., 2007) product; and the Japan Meteorological Agency's mesoscale model (MSM, $0.125^{\circ} \times 0.1^{\circ}$, 16 levels) for the period between 15 May and 15 June from 2007 to 2016 (2C-RAIN-PROFILE used only data un- til 2010). We used monthly mean top-of-atmosphere (TOA) and surface fluxes from the Clouds and the Earth's Radiant Energy System (CERES) Energy Budget Adjusted Fluxes (EBAF, $1^{\circ} \times 1^{\circ}$, Loeb et al., 2009) product for period between May and June from 2007 to 2016. This analysis period was selected because the SST gradient in the ECS is strongest during this time of the year, providing the greatest SST contrast between the Kuroshio and surrounding areas. The target region was a section of the ECS $\left(25-34^{\circ} \mathrm{N}, 120-131^{\circ} \mathrm{E}\right.$; the yellow square area shown in Fig. 1). Hereafter, areas with an SST warmer than $23.08^{\circ} \mathrm{C}$ were referred to as "ON Kuroshio" and those with temperatures below $23.08^{\circ} \mathrm{C}$ were referred to as "OFF Kuroshio" in May, and areas with an SST warmer than $24.70^{\circ} \mathrm{C}$ were referred to as "ON Kuroshio" and those with temperatures below $24.70^{\circ} \mathrm{C}$ were referred to as "OFF Kuroshio" in June. The thresholds were $1^{\circ}$ higher than the regional average temperatures in each month. The results did not significantly change when using 23 or $25^{\circ} \mathrm{C}$ as thresholds.

We defined "clouds" as layers with a cloud mask value between 30 and 40. An increase in the cloud mask indicated the reduced probability of false detection. Cloud mask values between 30 and 40 represented high-confidence detections ( $<2 \%$ false detections). In this study, we defined thick clouds with a geometric thickness $>6 \mathrm{~km}$ as convective clouds. For classification purposes, we adopted three precipitation categories: non-precipitating, drizzle, and precipitating, corresponding to radar reflectivity $<-15 \mathrm{dBZ},-15<$ radar reflectivity $<0 \mathrm{dBZ}$, and radar reflectivity $>0 \mathrm{dBZ}$, respectively (e.g., Frisch et al., 1995; L'Ecuyer et al., 2009; Suzuki et al., 2011). Lower-tropospheric stability (LTS) was defined as the difference in potential temperatures between $700 \mathrm{hPa}$ and surface (Klein and Hartmann, 1993) using ECMWF-AUX.

\section{Results}

\subsection{Mean atmospheric conditions and cloud properties in the ECS}

Before examining the influence of the Kuroshio on cloud structure, we first describe the influence of the Kuroshio on atmospheric conditions. Figure 1a shows the average wind convergence from the MSM at $1000 \mathrm{hPa}$ for the target period. Figure 1d presents the mean skin temperature from ECMWFAUX. Wind convergence was found at warmer flank around the Kuroshio front. Figure 1b shows the mean upward velocity of the MSM at $400 \mathrm{hPa}$. Strong updrafts occurred in the ECS during the target period and were strongest at $400 \mathrm{hPa}$. This observation was consistent with a previous report (Sasaki et al., 2012). Figure 1c shows the mean relative humidity of the MSM at $400 \mathrm{hPa}$. Relative humidity around the Kuroshio was higher than the domain of ECS, with the exception of the Kuroshio. Figure 1e presents the mean LTS 
(a) Wind conv. $1000 \mathrm{hPa}$

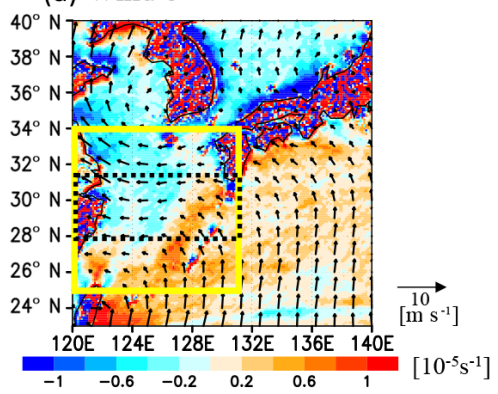

(b) $\quad-(0) 400 \mathrm{hPa}$

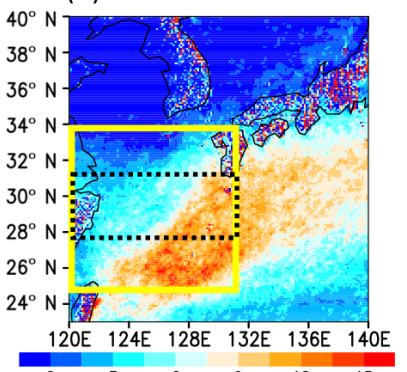

(c) $\mathrm{RH} 400 \mathrm{hPa}$

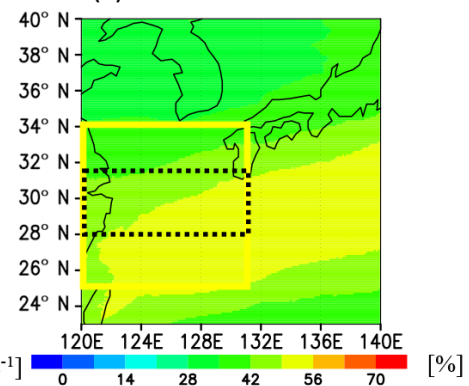

(d) Skin temp.

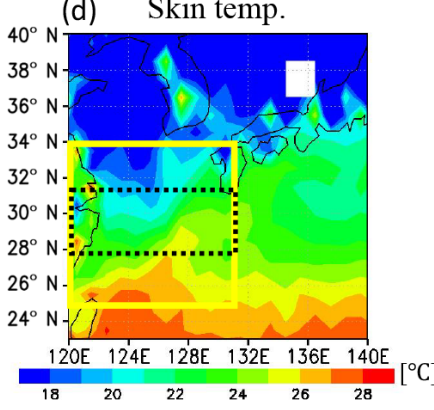

(e)

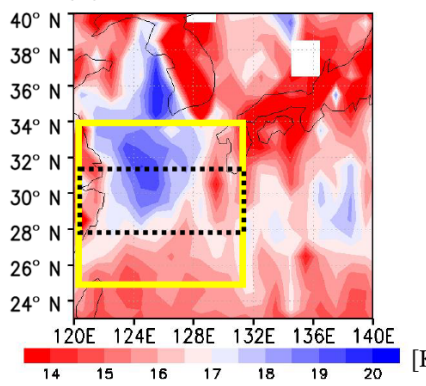

(f) Cloud fraction

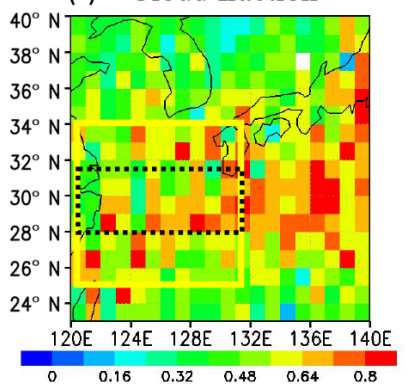

(g) Cloud fraction

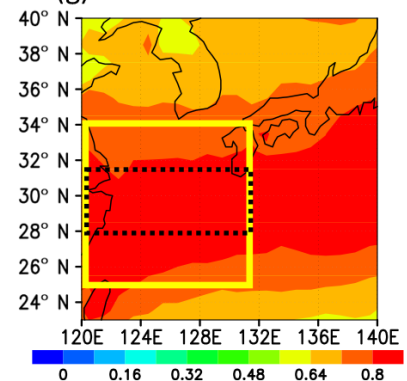

Figure 1. (a) Mean wind convergence (divergence) at $1000 \mathrm{hPa}$ (color; $10^{-5} \mathrm{~s}^{-1}$ ) and wind vector (vector; ms ${ }^{-1}$ ); (b) upward pressure velocity at $400 \mathrm{hPa}:-\omega\left(10^{-2} \mathrm{Pas}^{-1}\right)$; (c) relative humidity at $400 \mathrm{hPa}(\%)$ for the target period from the Japan Meteorological Agency's mesoscale model (MSM). (d) Mean skin temperature $\left({ }^{\circ} \mathrm{C}\right)$, (e) lower-tropospheric stability (K), and (f) cloud fraction for the target period using CloudSat products. (g) Cloud fraction for the target period using Aqua/MODIS products.

using ECMWF-AUX. LTS over the Kuroshio was significantly lower compared to around Kuroshio. Figure 1f shows the mean cloud fraction of the CloudSat cloud mask (from 2B-GEOPROF). Figure $1 \mathrm{~g}$ shows the mean cloud fraction of the Aqua/MODIS product. Cloud fraction was mostly high over the Kuroshio, although it was high throughout the ECS. CloudSat is unable to detect geometrically thin clouds and has a difficulty in measuring low clouds due to the surface echo, and then cloud fraction of CloudSat could have a possibility of underestimation compared to that of MODIS.

Figure $2 \mathrm{a}$ shows the mean precipitation rate from TMPA. The mean precipitation rate in target period reached 10$12 \mathrm{~mm}$ day $^{-1}$ over the Kuroshio, and it was twice as large as that in the surrounding Kuroshio area $\left(5-6 \mathrm{~mm}\right.$ day $\left.^{-1}\right)$. Figure $2 \mathrm{~b}$ and $\mathrm{c}$ shows mean water (Fig. 2b) and ice (Fig. 2c) cloud effective radius $\left(r_{\mathrm{e}}\right)$ from Aqua/MODIS. Water $r_{\mathrm{e}}$ was larger over the Kuroshio compared to the surrounding Kuroshio area; on the other hand, ice $r_{\mathrm{e}}$ was smaller over the Kuroshio compared to the surrounding Kuroshio area. Those results showed the cloud particle growth processes over the Kuroshio differed between ice and water clouds. Figure $2 \mathrm{~d}-\mathrm{f}$ shows the cloud optical thickness of all clouds, water clouds, and ice clouds from Aqua/MODIS. COT increased over the Kuroshio, which is particularly remarkable for water clouds.

Figure 3a shows the outgoing longwave radiation (OLR) at top of atmosphere from EBAF, and OLR decreases over the
Kuroshio. This result suggested that many clouds had high cloud top over the Kuroshio. Figure 3b shows reflected shortwave radiation at TOA, and the reflectance of shortwave radiation in the atmosphere increases over the Kuroshio. Cloud albedo increased as COT increased, and reflectance increased as cloud albedo increased. The cooling effect worked at TOA over the Kuroshio. Figure $3 c$ shows the net radiation flux at TOA, and it decreases over the Kuroshio. Figure $3 d$ and e shows longwave (LW) and shortwave (SW) radiation flux at the surface. Both longwave and shortwave fluxes decreased over the Kuroshio. Figure $3 \mathrm{f}$ shows net radiation flux at the surface, and it deceases over the Kuroshio. The cooling effect worked at the surface over the Kuroshio in the same manner as TOA.

In addition to this result, the data presented in the thick dotted square $\left(28-31.5^{\circ} \mathrm{N}, 120-131^{\circ} \mathrm{E}\right)$ of Fig. 1 were divided into 11 meridional vertical sections: the average wind convergence (Fig. 4a), the mean upward velocity (Fig. 4b), the mean relative humidity (Fig. 4c), the cloud fraction (Fig. 4d), the mean cloud liquid water content (CWC; Fig. 4e), the mean precipitating liquid water content (Fig. 4f), the mean precipitating ice water content (Fig. $4 \mathrm{~g}$ ), the mean total water content (TWC; Fig. 4h), the mean shortwave cloud radiative heating rate (Fig. 4i), the mean longwave cloud radiative heating rate (Fig. $4 \mathrm{j}$ ), and the mean net cloud radiative heating rate (Fig. $4 \mathrm{k}$ ). Wind convergence (Fig. $4 \mathrm{a}$ ) 
(a) Precipitation rate

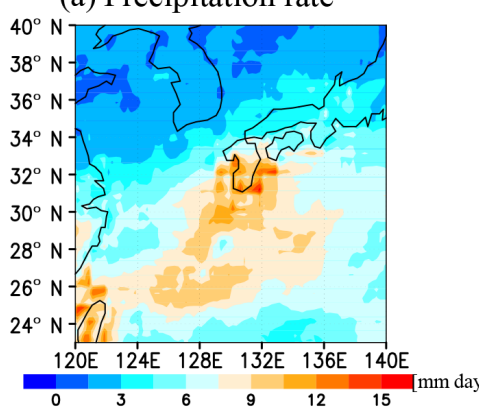

(b) $r_{\mathrm{e}}$ [water]

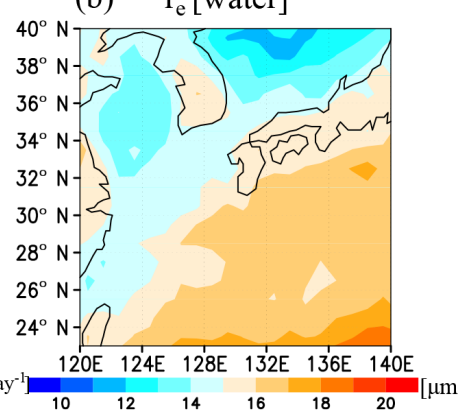

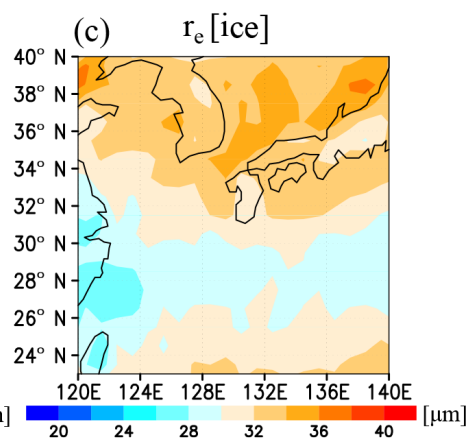

(f) $\quad$ COT [ice]

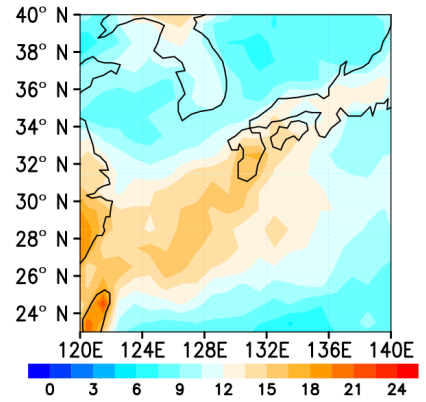

Figure 2. (a) Mean precipitation rate $\left(\mathrm{mm} \mathrm{day}^{-1}\right)$ from TRMM. (b) Mean water cloud effective radius $(\mu \mathrm{m})$, (c) mean ice cloud effective radius $(\mu \mathrm{m})$, (d) mean all-cloud optical thickness, (e) mean water cloud optical thickness, and (f) mean ice cloud optical thickness for the target period using Aqua/MODIS products.

was found from the lower troposphere over the Kuroshio $\left(126-130^{\circ} \mathrm{E}\right)$, and the mean upward velocity (Fig. 4b) was strongest around $400 \mathrm{hPa}$ over the Kuroshio and became weak or negative at lower longitudes. The relative humidity (Fig. 4c) in the lower to upper troposphere over the Kuroshio was higher than the west side of the Kuroshio (west of $126^{\circ} \mathrm{E}$ ). The cloud fraction (Fig. 4d) in the lower to upper troposphere was high in the ECS as a whole, and there was no clear difference between over the Kuroshio and around the Kuroshio. Note that Fig. 4d is a frequency of the presence of clouds, and it is not related to the rainfall intensity. We observed that the precipitating liquid and ice water content (Fig. 4f and g) were high from the lower to the middle troposphere $(0.5-6 \mathrm{~km})$ over the east-side area of the SST front of the Kuroshio $\left(126^{\circ} \mathrm{E}\right)$. However, the cloud liquid water content did not show a clear difference between over the Kuroshio and around the Kuroshio. The Kuroshio affected the lower to middle-level PLWC and PIWC inside clouds more than the CWC (Fig. 4e and g). The total water content (TWC: CWC + PLWC + PIWC) corresponded to LTS. LTS peaked around $124.5^{\circ} \mathrm{E}$, and TWC was the lowest there. In addition, TWC increased with decreasing LTS. The stronger upward motion and lower LTS over the Kuroshio could change the PLWC, PIWC, and TWC.

Finally, we considered the influence of clouds over the Kuroshio on atmospheric radiative processes. Shortwave ra- diative absorption and longwave radiative emission act to heat and cool the atmosphere, respectively (Fig. $4 i$ and j). Radiative heating occurred due to shortwave radiation inside the cloud, while radiative cooling occurred due to longwave radiation around the cloud top (Yoshida et al., 2004). Shortwave cloud radiative heating and longwave cloud radiative cooling were both strong at the higher altitudes over the Kuroshio $\left(126-128^{\circ}\right.$ E, Fig. $4 i$ and j). Strong shortwave cloud radiative heating occurred in the middle to upper layer $(7-15 \mathrm{~km}$, Fig. 4i), while strong longwave radiative cooling occurred in the upper layer (14-15 km, Fig. 4j) over the Kuroshio. In summary, net radiative heating over the Kuroshio occurred at a height of around $14 \mathrm{~km}$ (Fig. 4k). As previously described, TWC increased over the Kuroshio. Shortwave radiative absorption inside the cloud was enhanced by this change, with Stephens (1978) suggesting that it increased as the total amount of cloud water increased. From this analysis, it was concluded that clouds over the Kuroshio had a role in heating the atmosphere at higher altitudes.

\subsection{Two-dimensional probability density function and contoured frequency by altitude diagrams}

In this section, we discuss the effects of altitude on rainfall intensity over the Kuroshio. Figure 5a-c shows the twodimensional probability density function of radar reflectivity, 
(a) TOA OLR

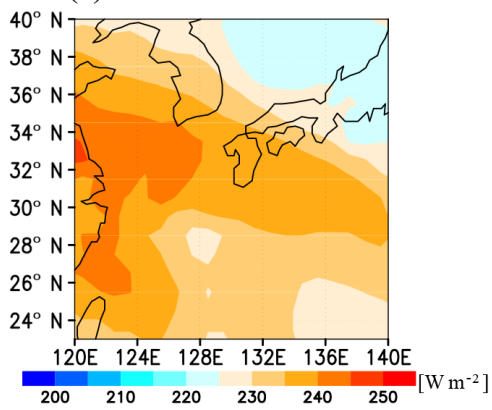

(d) Surface LW flux

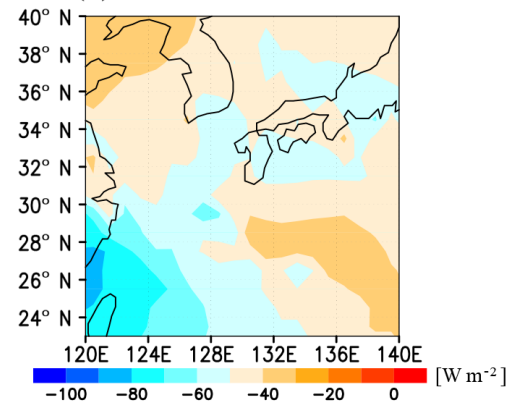

(b) TOA reflected SW

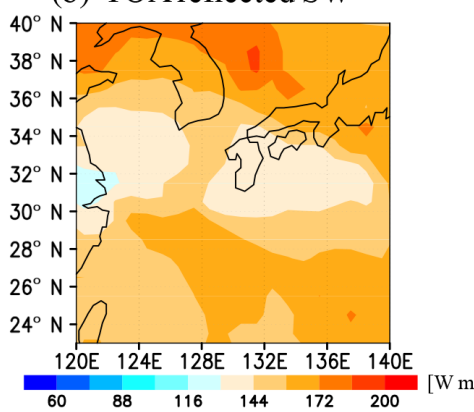

(e) Surface SW flux

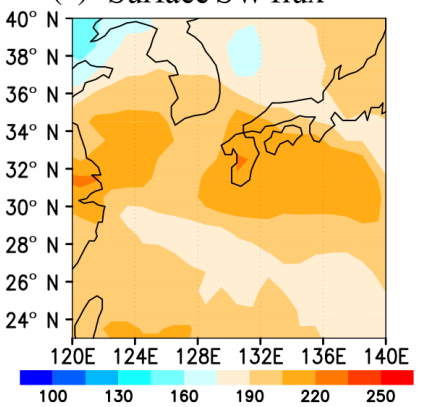

(c) TOA net flux

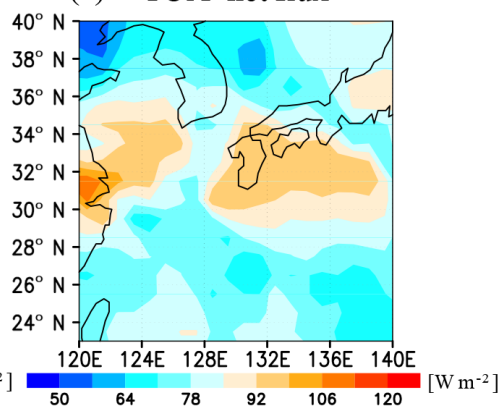

(f) Surface net flux

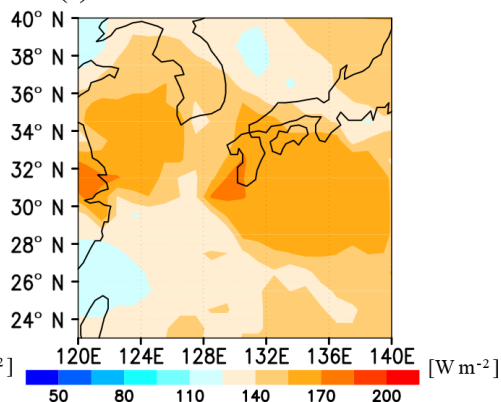

Figure 3. (a) Mean outgoing longwave radiation (OLR) at top of atmosphere (TOA) $\left(\mathrm{Wm}^{-2}\right)$, (b) mean reflected shortwave radiation at TOA $\left(\mathrm{W} \mathrm{m}^{-2}\right)$, (c) mean net $(\mathrm{SW}+\mathrm{LW})$ radiation at TOA $\left(\mathrm{W} \mathrm{m}^{-2}\right)$, (d) mean net longwave radiation at surface $\left(\mathrm{W} \mathrm{m}^{-2}\right)$, (e) mean net shortwave radiation at surface $\left(\mathrm{W} \mathrm{m}^{-2}\right)$, and (f) mean net radiation at surface $\left(\mathrm{W} \mathrm{m}^{-2}\right)$ for the target period using EBAF products.

and Fig. 5d-f showed the contoured frequency by altitude diagrams (CFADs, Yuter and Houze, 1995). CFADs are defined as the probability distribution of radar reflectivity normalized at each altitude. CFADs can get information on precipitation intensity for each altitude. Only the lowest cloud in each CloudSat profile was included in the analysis, and the target region was a section of the ECS $\left(25-34^{\circ} \mathrm{N}, 120\right.$ $131^{\circ} \mathrm{E}$; the yellow square area shown in Fig. 1). The peak frequency of occurrence lay around 0 to $15 \mathrm{dBZ}$ and 1 to $6 \mathrm{~km}$ (Fig. 5a and b). These results showed that clouds with the highest rainfall intensity measurable by CloudSat at lower altitudes $(1-6 \mathrm{~km})$ are common in the target region. The radar reflectivity was weak $(<0 \mathrm{dBZ})$ for both $\mathrm{ON}$ and OFF Kuroshio in the lower layer, but gradually became stronger ( $>0 \mathrm{dBZ}$ ) closer to the middle layer $(\sim 6 \mathrm{~km})$ as the altitude increased (Fig. $5 \mathrm{~d}$ and e). Above $6 \mathrm{~km}$, the radar reflectivity weakened as the altitude increased. Although ON and OFF Kuroshio showed similar tendencies, some differences were evident (Fig. 5c and f). High radar reflectivity was more common in OFF Kuroshio up to $\sim 6 \mathrm{~km}$, and heavy precipitation below $6 \mathrm{~km}$ was reduced but there is more drizzle over the Kuroshio (Fig. 5c and f). These differences were statistically significant at a $95 \%$ confidence level using Student's $t$ test. These results indicate that the altitude of the peak rainfall intensity was different between ON and OFF Kuroshio, and the Kuroshio affected the clouds in the middle tropo- sphere. The radar reflectivity of the middle clouds (around $6 \mathrm{~km}$ ) was higher ON Kuroshio than OFF Kuroshio. At midaltitudes, the average precipitation intensity was stronger for ON Kuroshio than for OFF Kuroshio.

\subsection{Relationship between cloud geometric thickness and radar reflectivity}

In this section, we discuss the relationship between cloud geometrical thickness and rainfall properties inside the cloud. The difference in the frequency (ON Kuroshio-OFF Kuroshio) of the geometric thicknesses is shown in Fig. 6 according to three categories of maximum radar reflectivity (MaxZe) for (a) non-precipitating (MaxZe $<-15 \mathrm{dBZ}$ ), (b) drizzle $(-15<$ MaxZe $<0 \mathrm{dBZ})$, and (c) precipitating (MaxZe > 0 dBZ) clouds. Here, the MaxZe refers to the maximum radar reflectivity value in the cloud. These thresholds for the occurrence of precipitation were taken from L'Ecuyer et al. (2009). Only the lowest cloud in each CloudSat profile was included in the analysis, and the target region was a section of the ECS $\left(25-34^{\circ} \mathrm{N}, 120-131^{\circ} \mathrm{E}\right.$; the yellow square area shown in Fig. 1). The non-precipitating clouds included many geometrically thin clouds both $\mathrm{ON}$ and OFF Kuroshio, and the drizzle and the precipitating clouds included many geometrically thick clouds. The fraction of occurrence of non-precipitating clouds was not much different 

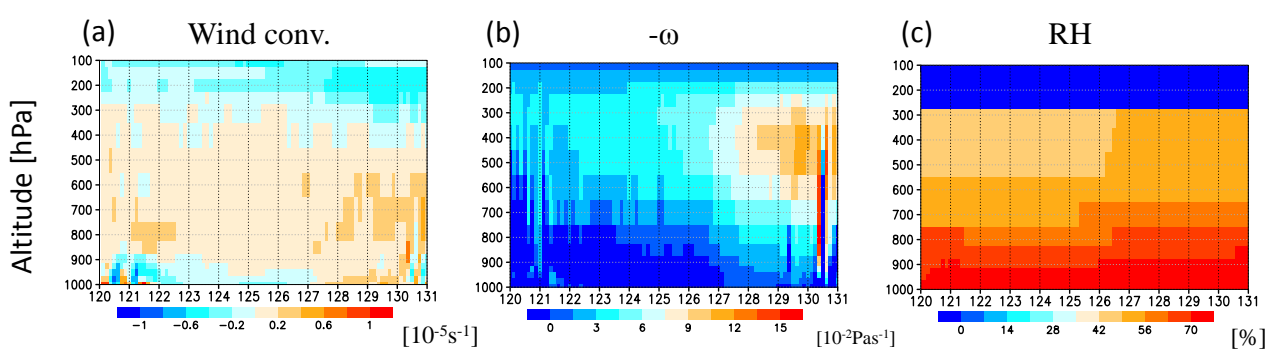

(d) Cloud fraction

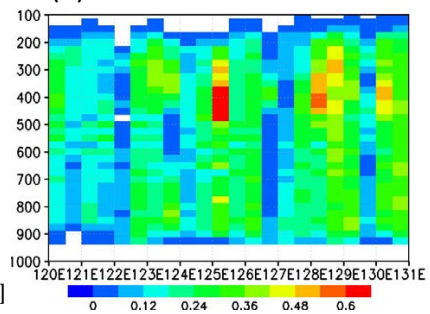

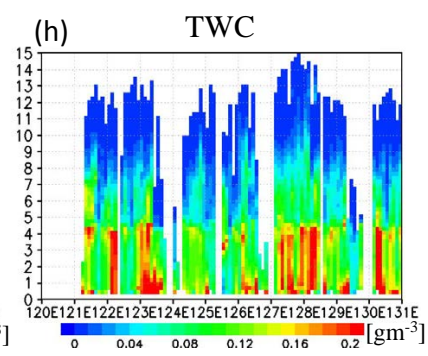
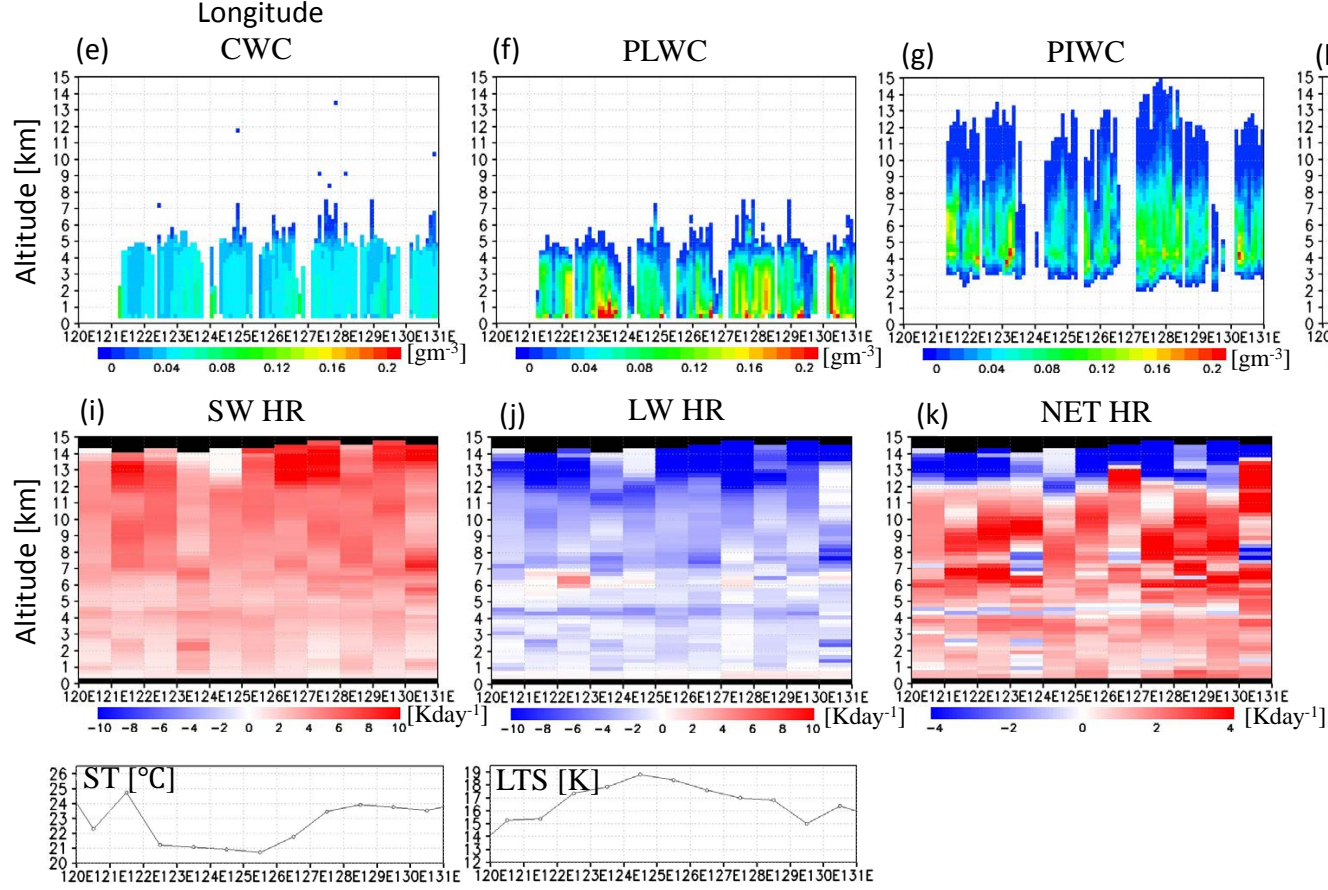

Figure 4. The meridional vertical sections in the thick dotted square $\left(28-31.5^{\circ} \mathrm{N}, 120-131^{\circ} \mathrm{E}\right)$ of Fig. 1a. (a) Mean wind convergence (divergence) at $1000 \mathrm{hPa}\left(10^{-5} \mathrm{~s}^{-1}\right)$, (b) upward pressure velocity at $400 \mathrm{hPa}:-\omega\left(10^{-2} \mathrm{~Pa} \mathrm{~s}^{-1}\right)$, (c) relative humidity at $400 \mathrm{hPa}(\%)$ for the target period from the Japan Meteorological Agency's mesoscale model (MSM). (d) Mean cloud fraction, (e) cloud water content ( $\mathrm{g} \mathrm{m}^{-3}$ ), (f) precipitating liquid water content $\left(\mathrm{g} \mathrm{m}^{-3}\right)$, (g) precipitating ice water content $\left(\mathrm{g} \mathrm{m}^{-3}\right)$, (h) total water content $\left(\mathrm{g} \mathrm{m}^{-3}\right)$, (i) shortwave cloud radiative heating rate $\left(\mathrm{K}\right.$ day $^{-1}$, upper panel) and skin temperature $\left({ }^{\circ} \mathrm{C}\right.$, lower panel), (j) longwave cloud radiative heating rate $\left(\mathrm{K}\right.$ day ${ }^{-1}$, upper panel) and lower-tropospheric stability $\left(\mathrm{K}\right.$, lower panel), and $(\mathbf{k})$ net $(\mathrm{SW}+\mathrm{LW})$ cloud radiative heating rate $\left(\mathrm{K}^{\text {day }}{ }^{-1}\right)$ using CloudSat products.

between ON and OFF Kuroshio (Fig. 6a). The drizzle clouds over ON Kuroshio have a higher chance of being geometrically thin $(0.5-3 \mathrm{~km})$ and thicker $(7-10 \mathrm{~km})$ compared to those over OFF Kuroshio (Fig. 6b). The drizzle clouds over ON Kuroshio exist in geometrically thin and thick cases. Rainfall intensity of thin clouds over ON Kuroshio could be enhanced by the Kuroshio. In addition, the frequency of occurrence of the precipitating clouds with a geometric thickness of 7 to $10 \mathrm{~km}$ significantly increased ON Kuroshio. Geometrically thick clouds occurred more because strong updrafts (Fig. 2a) took place over the Kuroshio. Precipitating clouds reveal a distinct difference between the ON and OFF Kuroshio regions, with the Kuroshio considered to have a more significant impact on drizzle and precipitating clouds than on non-precipitating clouds. Consequently, these geo- metrically thick clouds with precipitation inside the cloud could be caused by stronger updrafts over the Kuroshio; additionally, these clouds corresponded to the convective rain clouds reported by Miyama et al. (2012).

\subsection{Relationship between maximum radar reflectivity position and radar reflectivity}

Figure 7a-c shows the relationship between the fraction of the maximum radar reflectivity (MaxZe) position and altitude according to the three categories (non-precipitating, drizzle, and precipitating) of MaxZe. Only the lowest cloud in each CloudSat profile was included in the analysis, and the target region was a section of the ECS $\left(25-34^{\circ} \mathrm{N}, 120\right.$ $131^{\circ} \mathrm{E}$; the yellow square area shown in Fig. 1). The fraction of the MaxZe position in non-precipitating clouds reaches 


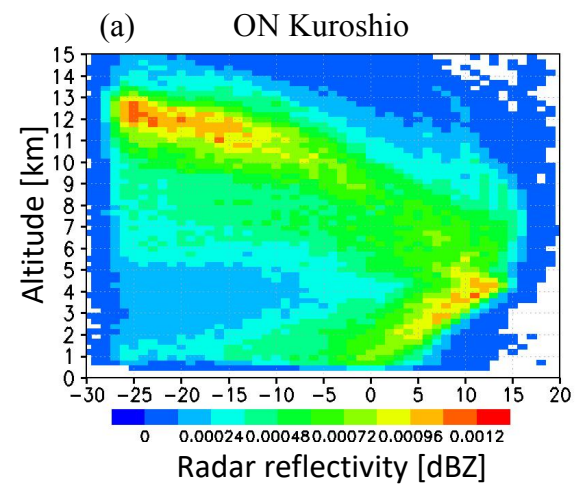

(b) OFF Kuroshio

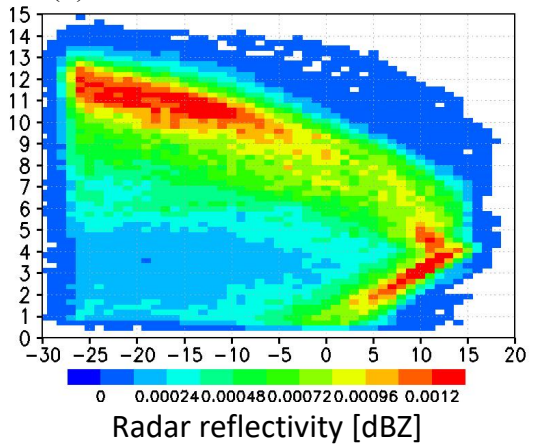

(e)

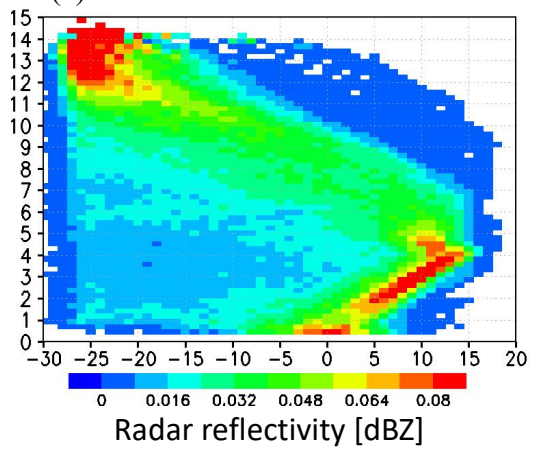

(c) Diff. ON-OFF Kuroshio

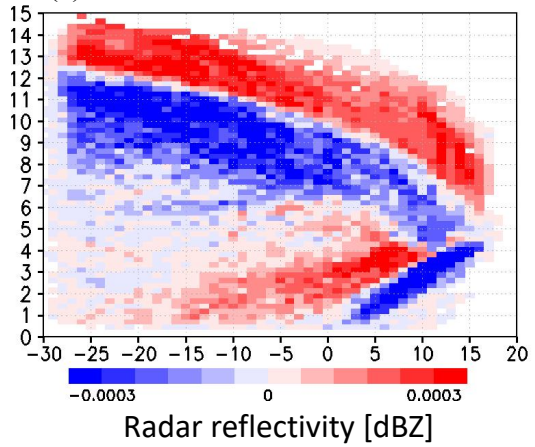

(f) Diff. ON-OFF Kuroshio

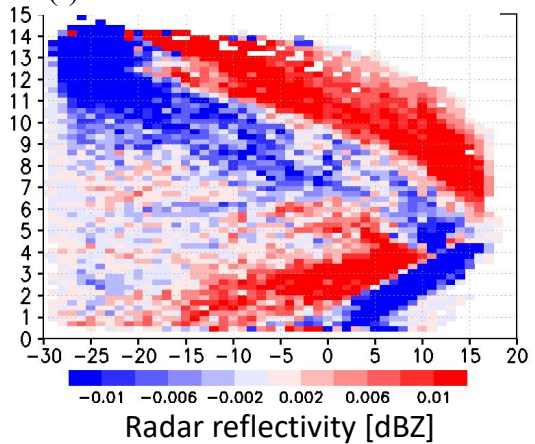

Figure 5. Two-dimensional probability density function for (a) ON Kuroshio, (b) OFF Kuroshio, and (c) ON-OFF Kuroshio, and contoured frequency by altitude diagrams (CFADs) for (d) ON Kuroshio, (e) OFF Kuroshio, and (f) ON Kuroshio-OFF Kuroshio.

\section{Non-precipitating}

(a)

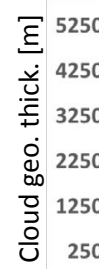

$\operatorname{MaxZe}<-15 \mathrm{dBZ}$

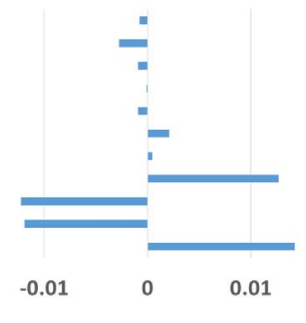

Different in frequency
Drizzle

(b) $-15 \mathrm{dBZ}<\operatorname{MaxZe}<0 \mathrm{dBZ}$

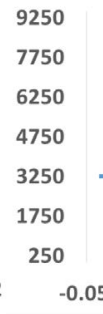

$-0.05$

Different in frequency

\section{Precipitating}

(c) $\quad 0 \mathrm{dBZ}<$ MaxZe
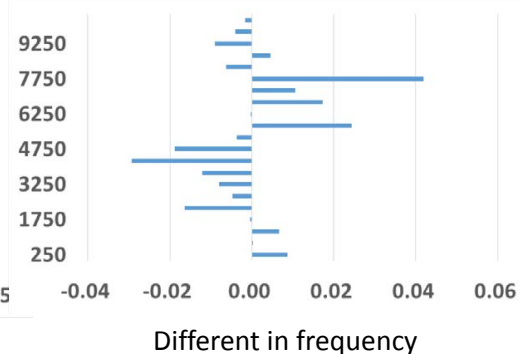

Different in frequency

Figure 6. Difference in the frequency of the geometrical thickness (ON Kuroshio-OFF Kuroshio) according to three categories of MaxZe for (a) non-precipitating, (b) drizzle, and (c) precipitating.

a peak around high altitude $(10-12 \mathrm{~km})$. As MaxZe increased, the altitude of MaxZe position decreased. In the case of non-precipitating clouds, the fraction of MaxZe in the lower layer ( 2 to $5 \mathrm{~km}$ ) over the Kuroshio slightly increases compared to OFF Kuroshio. These results showed that the high relative humidity and the dynamic vertical motion over the Kuroshio could influence clouds from the lower troposphere.

To determine the relative position of MaxZe in clouds, vertical normalization was undertaken such that the cloud top is 0 and the cloud base is 1 . Each $240 \mathrm{~m}$ thick cloud layer was assigned to 10 sublayers between the cloud top (0) and the cloud base (1). In this analysis, we used clouds with more than three layers. For example, for the three-layer cloud, the first, second, and third layers were assigned $0,0.5$, and 1 , respectively. For the five-layer cloud, the first, second, third, fourth, and fifth layers were assigned 0, 0.25, 0.5, 0.75, and 1 , respectively. For example, when the second layer in the fifth layer cloud shows the maximum radar reflectivity, the vertical normalization was rounded off to 0.3 . Figure $5 \mathrm{~d}-\mathrm{f}$ shows the fraction of the MaxZe position for the scaled cloud layer according to the three categories of MaxZe. The horizon- 


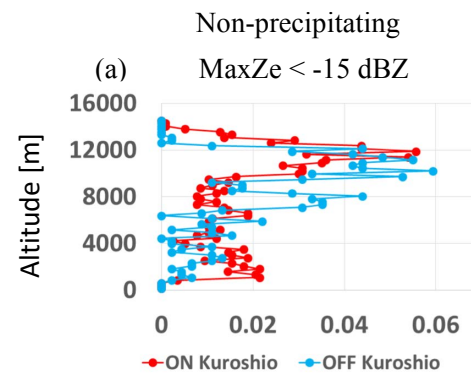

Fraction of MaxZeposition

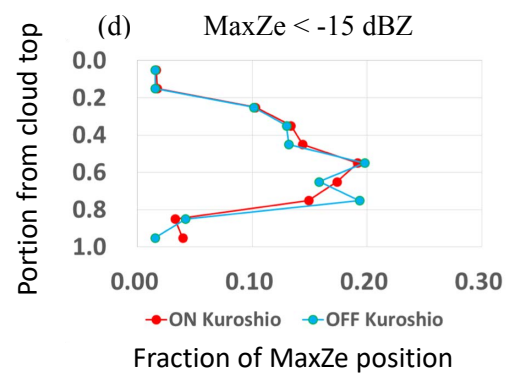

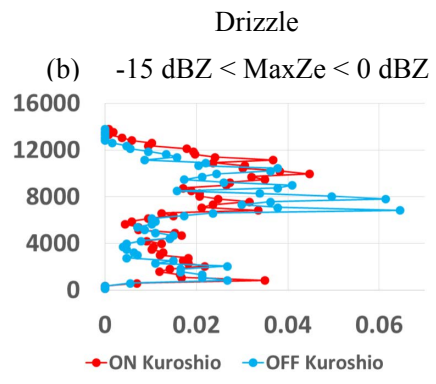

Fraction of MaxZeposition

(e) $-15 \mathrm{dBZ}<$ MaxZe $<0 \mathrm{dBZ}$

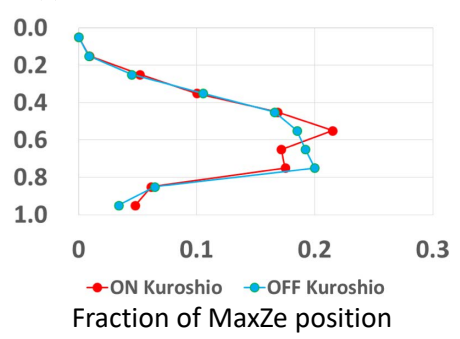

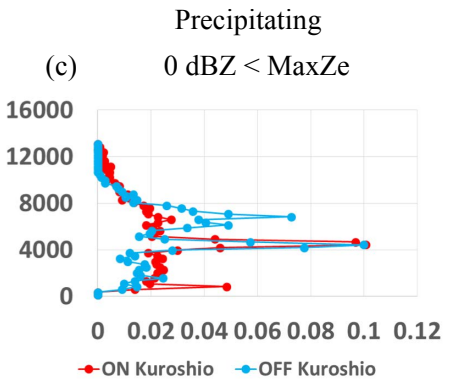

Fraction of MaxZeposition

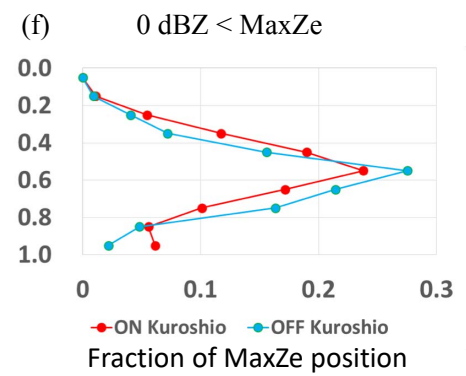

Figure 7. The relationship between the fraction of the maximum radar reflectivity (MaxZe) position and altitude according to the three categories of MaxZe for (a) non-precipitating, (b) drizzle, and (c) precipitating clouds. The fraction of the MaxZe position for the scaled cloud layer according to the three categories of MaxZe for (d) non-precipitating, (e) drizzle, and (f) precipitating clouds.

tal axis is the fraction of the MaxZe position, and the vertical axis was the relative position from the cloud top. The radar reflectivity almost reaches a maximum near the center of the cloud (Fig. 7d-f). However, characteristics of drizzle and precipitating clouds were slightly different between $\mathrm{ON}$ and OFF Kuroshio. The MaxZe position in the drizzle and precipitating clouds over ON Kuroshio is higher than OFF Kuroshio (Fig. 7e and f). On the one hand, stronger updrafts over the land maintained large droplets higher in the upper part of the cloud layer. On the other hand, drizzle and rain appear to form lower down in the oceanic cloud layers due to the weaker updrafts (Nakajima et al., 2010). We consider that clouds over the Kuroshio grow in the upper part of the cloud layer due to the strong updraft, such as land clouds. The cloud particles grew in the precipitating clouds at the center part from the top of the cloud through the collisional growth and gradually fell due to gravity. The growth process of cloud particles occurred from the central to lower part of the cloud. However, MaxZe would be reached at the center of the cloud with an attenuation of radar reflectivity using the existence of the large particles in the lower part of the cloud.

\section{Summary and conclusions}

This study clarified the effects of SST changes in the Kuroshio Current on the vertical structure of clouds using CloudSat products and meteorological data. Surface wind convergence, strong updrafts from the lower to the middle troposphere, and high relative humidity occurred over the
Kuroshio for the target period. The precipitation rate, water $r_{\mathrm{e}}$, COT, and radiative cooling effect at the TOA and surface increased over the Kuroshio. Moreover, we observed that the area with high water content and radiative heating values increased with increasing (decreasing) skin temperature (LTS). We showed that the strength of precipitation inside the cloud increased around the middle layers (about $6 \mathrm{~km}$ ) compared to that in the upper layer. The influence of the Kuroshio on precipitation intensity extended to the middle atmosphere. The drizzle clouds over ON Kuroshio have a higher chance of being geometrically thin $(0.5-3 \mathrm{~km})$ and thicker $(7-10 \mathrm{~km})$ compared to those over OFF Kuroshio. Moreover, the frequency of occurrence of the precipitating clouds with a geometric thickness of 7 to $10 \mathrm{~km}$ increased over ON Kuroshio. Those clouds were geometrically thick, and the precipitating liquid water content and rainfall intensity increased inside the cloud. Strong updrafts over the Kuroshio could maintain large droplets higher in clouds in the upper layer, and the MaxZe position in non-precipitating and drizzle clouds over the Kuroshio was higher than that around the Kuroshio.

These results showed that the vertical structures (rainfall intensity, cloud geometrical thickness, and MaxZe position) of clouds were distinctly different between over the Kuroshio and around the Kuroshio. We consider that the difference in the MaxZe position may help to better understand the cloud-to-precipitation transitional process over the Kuroshio. A correct understanding of the transition process from cloud to precipitation can contribute to reducing bias with obser- 
vations in the GCMs (e.g., Michibata and Takemura, 2015; Michibata et al., 2016). Because we focused on only local phenomena over the Kuroshio in this study, our results may have some limitations when extending to global applications. Recently, the non-hydrostatic icosahedral atmospheric model (NICAM; e.g., Tomita and Satoh, 2004; Satoh et al., 2008) has made it possible to reproduce cloud-related phenomena with a horizontal resolution of less than $1 \mathrm{~km}$ (Miyamoto et al., 2013). Furthermore, a hybrid microphysical cloud model with a two-moment bin method (Kuba and Fujiyoshi, 2006; Kuba and Murakami, 2010) has been developed; therefore, the understanding of the smaller-scale phenomena is crucially necessary. Incorporating the results of this study into these models would greatly improve the accuracy of model simulations through motivating better representations of the rainfall parameterization and physically based process description. Quantitative assessment of the influence of local SST gradient on cloud and atmospheric conditions is now a fundamentally important question in addition to its detection as done in this study.

Consequently, we concluded that the Kuroshio influences not only the dynamical processes of the lower layer of the atmosphere but also the properties inside clouds. The Earth Clouds, Aerosols, and Radiation Explorer (EarthCARE) satellite is scheduled for launch in 2019. This satellite will carry a new CPR that measures the upward and downward flow velocities inside a cloud while observing its vertical structure (Illingworth et al., 2015). EarthCARE will be able to detect thinner clouds, and its Doppler capability will provide useful information on convection, precipitating ice particles, and rainfall speeds. The cloud physical properties on the Kuroshio can probably be clarified in more detail with the data from EarthCARE.

Data availability. The CloudSat datasets are available from the CloudSat Data Processing Center of the Cooperative Institute for Research in the Atmosphere (http://www.cloudsat.cira.colostate. edu/). Aqua/MODIS and TRMM products are available from the Giovanni online data system, developed and maintained by the NASA GES DISC (https://giovanni.gsfc.nasa.gov/giovanni/). CERES/EBAF products are available from the NASA Langley Research Center (https://ceres.larc.nasa.gov/). MSM products are available from the Research Institute for Sustainable $\mathrm{Hu}$ manosphere, Kyoto University (http://database.rish.kyoto-u.ac.jp/ index-e.html).

Competing interests. The authors declare that they have no conflict of interest.

Acknowledgements. The CloudSat data products of 2B-GEOPROF, 2C-RAIN-PROFILE, 2B-FLXHR, and ECMWF-AUX were provided by the CloudSat Data Processing Center at the Cooperative Institute for Research in the Atmosphere, Colorado State Univer- sity. Aqua/MODIS and TRMM products were provided by the Giovanni online data system, developed and maintained by the NASA GES DISC. CERES/EBAF products were provided by the NASA Langley Research Center. MSM products were provided by the Research Institute for Sustainable Humanosphere, Kyoto University. This study was supported by the Japanese Ministry of Education, Culture, Sports, Science and Technology (MEXT) through the Grant-in-Aid for Scientific Research in Innovative Areas 2205 and the Japan Society for the Promotion of Science (JSPS) KAKENHI grant numbers 16H01844, 16H04046, and 17H02958.

Edited by: Timothy Garrett

Reviewed by: two anonymous referees

\section{References}

Dufresne, J. L. and Bony, S.: An assessment of the primary sources of spread of global warming estimates from coupled atmosphere-ocean models, J. Climate, 21, 5135-5144, 2008.

Frisch, A. S., Fairall, C. W., and Snider, J. B.: Measurement of stratus cloud and drizzle parameters in ASTEX with a $\mathrm{K} \alpha$-band Doppler radar and a microwave radiometer, J. Atmos. Sci., 52, 2788-2799, https://doi.org/10.1175/15200469(1995)052<2788:MOSCAD>2.0.CO;2, 1995.

Haynes, J. M., L'Ecuyer, T. S., Stephens, G. L., Miller, S. D., Mitrescu, C., Wood, N. B., and Tanelli, S.: Rainfall retrieval over the ocean with spaceborne W-band radar, J. Geophys. Res., 114, D00A22, https://doi.org/10.1029/2008JD009973, 2009.

Huang, Y., Steven, T. S., Michael, J. M., Rosenfeld, D., Marchand, R., McFarquhar, G. M., and Protat, A.: What is the role of sea surface temperature in modulating cloud and precipitation properties over the Southern Ocean?, J. Climate, 29, 7453-7476, https://doi.org/10.1175/JCLI-D-15-0768.1, 2016.

Huffman, G. J.: Estimates of root-mean-square random error for finite samples of estimated precipitation, J. Appl. Meteorol. Clim., 36, 1191-1201, 1997.

Huffman, G. J., Adler, R. F., Bolvin, D. T., Gu, G., Nelkin, E. J., Bowman, K. P., Hong, Y., Stocker, E. F., and Wolff, D. B.: The TRMM Multi-satellite precipitation analysis: quasi-global, multi-year, combined-sensor precipitation estimates at fine scale, J. Hydrometeorol., 8, 38-55, 2007.

Illingworth, A. J., Barker, H. W., Baljaars, A., Ceccaldi, M., Chepfer, H., Cole, J., Delanoe, J., Domenth, C., Donovan, D. P., Fukuda, S., Hirakata, M., Hogan, R. J., Huenerbein, A., Kollias, P., Kubota, T., Nakajima, T., Nakajima, T. Y., Nishizawa, T., Ohno, Y., Okamoto, H., Oki, R., Sato, K., Satoh, M., Shephard, M., Wandinger, U., Wehr, T., and van Zadelhoff, G.-J.: The EarthCARE Satellite: the next step forward in global measurements of clouds, aerosols, precipitation and radiation, B. Am. Meteorol. Soc., 96, 1311-1332, https://doi.org/10.1175/BAMSD-12-00227.1, 2015.

Kawamoto, K. and Hayasaka, T.: Relative contributions to surface shortwave irradiance over China: a new index of potential radiative forcing, Geophys. Res. Lett., 35, L17809, https://doi.org/10.1029/2008GL035083, 2008.

Klein, S. and Hartmann, D. L.: The seasonal cycle of low stratiform clouds, J. Climate, 6, 1587-1606, 1993. 
Kuba, N. and Fujiyoshi, Y.: Development of a cloud microphysical model and parameterizations to describe the effect of CCN on warm cloud, Atmos. Chem. Phys., 6, 2793-2810, https://doi.org/10.5194/acp-6-2793-2006, 2006.

Kuba, N. and Murakami, M.: Effect of hygroscopic seeding on warm rain clouds - numerical study using a hybrid cloud microphysical model, Atmos. Chem. Phys., 10, 3335-3351, https://doi.org/10.5194/acp-10-3335-2010, 2010.

Kunoki, S., Manda, A., Kodama, Y.-M., Iizuka, S., Sato, K., Fathrio, I., Mistui, T., Seko, H., Moteki, Q., Minobe, S., and Tachibana, Y.: Oceanic influence on the Baiu frontal zone in the East China Sea. J. Geophys. Res., 120, 449-463, https://doi.org/10.1002/2014JD022234, 2015.

Kuwano-Yoshida, A., Taguchi, B., and Xie, S.-P.: Baiu rainband termination in atmospheric and coupled atmosphere-ocean models, J. Climate, 26, 10111-10124, https://doi.org/10.1175/JCLID-13-00231.1, 2013.

Lebsock, M. D., Tristan, S., L'Ecuyer, T. S., and Stephens, G. L.: Detecting the ratio of rain and cloud water in low-latitude shallow marine clouds, J. Appl. Meteorol. Clim., 50, 419-432, 2011.

L'Ecuyer, T. S., Wood, N. B., Haladay, T., Stephens, G. L., and Stackhouse Jr., P. W.: Impact of clouds on atmospheric heating based on the R04 CloudSat fluxes and heating rates data set, J. Geophys. Res.-Atmos., 113, D00A15, https://doi.org/10.1029/2008JD009951, 2008.

L'Ecuyer, T. S., Berg, W., Haynes, J. M., Lebsock, M. D., and Takemura, T.: Global observations of aerosol impacts on precipitation occurrence in warm maritime clouds, J. Geophys. Res.-Atmos., 114, D09211, https://doi.org/10.1029/2008JD009835, 2009.

Liu, J., Xie, S., Yang, S., and Zhang, S.: Low-cloud transitions across the Kuroshio Front in the East China Sea, J. Climate, 29, 4429-4443, https://doi.org/10.1175/JCLI-D-15-0589.1, 2016.

Loeb, N. G., Wielicki, B. A., Doelling, D. R., Smith, G. L., Keyes, D. F., Kato, S., Manalo-Smith, N., and Wong, T.: Toward optimal closure of the Earth's top-of-atmosphere radiation budge, J. Climate, 22, 748-766, 2009.

Mace, G. G., Marchand, R., Zhang, Q., and Stephens, G. L.: Global hydrometeor occurrence as observed by CloudSat: initial observations from summer 2006, Geophys. Res. Lett., 34, L09808, https://doi.org/10.1029/2006GL029017, 2007.

Manda, A., Nakamura, H., Asano, N., Iizuka, S., Miyama, T., Moteki, Q., Yoshioka, M. K., Nishii, K., and Miyasaka, T.: Impacts of a warming marginal sea on torrential rainfall organized under the Asian summer monsoon, Sci. Rep.-UK, 4, 5741, https://doi.org/10.1038/srep05741, 2014.

Marchand, R., Mace, G. G., Ackerman, T., and Stephens, G. L.: Hydrometeor detection using CloudSat - an Earth-orbiting $94 \mathrm{GHz}$ cloud radar, J. Atmos. Ocean. Tech., 25, 519-533, 2008.

Michibata, T. and Takemura, T.: Evaluation of autoconversion schemes in a single model framework with satellite observations, J. Geophys. Res., 120, 9570-9590, https://doi.org/10.1002/2015JD023818, 2015.

Michibata, T., Suzuki, K., Sato, Y., and Takemura, T.: The source of discrepancies in aerosol-cloud-precipitation interactions between GCM and A-Train retrievals, Atmos. Chem. Phys., 16, 15413-15424, https://doi.org/10.5194/acp-16-154132016, 2016.
Mitrescu, C., L’Ecuyer, T. S., Haynes, J. M., Miller, S. D., and Turk, J.: CloudSat precipitation profiling algorithm-model description, J. Appl. Meteorol. Clim., 49, 991-1003, 2010.

Miyama, T., Nonaka, M., Nakamura, H., and Kuwano-Yoshida, A.: A striking early-summer event of a convective rainband persistent along the warm Kuroshio in the East China Sea, Tellus A, 64, 18962, https://doi.org/10.3402/tellusa.v64i0.18962, 2012.

Miyamoto, Y., Kajikawa, Y., Yoshida, R., Yamaura, T., Yashiro, H., and Tomita, H.: Deep moist atmospheric convection in a subkilometer global simulation, Geophys. Res. Lett., 40, 4922-4926, https://doi.org/10.1002/grl.50944, 2013.

Nakajima, T. Y., Suzuki, K., and Stephens, G. L.: Droplet growth in warm water clouds observed by the A-Train. Part II: A multisensor view, J. Atmos. Sci., 67, 1897-1907, 2010.

Nam, C., Bony, S., Dufresne, J. L., and Chepfer, H.: The "too few, too bright" tropical low-cloud problem in CMIP5 models, Geophys. Res. Lett., 39, L21801, https://doi.org/10.1029/2012GL053421, 2012.

Partain, P.: CloudSat ECMWF-AUX Auxiliary Data Process Description and Interface Control Document, Cooperative Institute for Research in the Atmosphere, Colorado State University, $11 \mathrm{pp}$, available at: http: //www.cloudsat.cira.colostate.edu/sites/default/files/products/ files/ECMWF-AUX_PDICD.P_R04.20070718.pdf (last access: May 2018), 2007.

Sasaki, Y. N., Minobe, S., Asai, T., and Inatsu, M.: Influence of the Kuroshio in the East China Sea on the early summer (Baiu) rain, J. Climate, 27, 6627-6645, 2012.

Sato, K., Manda, A., Moteki, Q., Komatsu, K. K., Ogata, K., Nishikawa, H., Oshika, M., Otomi, Y., Kunoki, S., Kanehara, H., Aoshima, T., Shimizu, K., Uchida, J., Shimoda, M., Yagi, M., Minobe, S., and Tachibana, Y.: Influence of the Kuroshio on mesoscale convective systems in the Baiu frontal zone over the East China Sea, Mon. Weather Rev., 144, 1017-1033, https://doi.org/10.1175/MWR-D-15-0139.1, 2016.

Satoh, M., Matsuno, T., Tomita, H., Miura, H., Nasuno, T., and Iga, S.: Nonhydrostatic Icosahedral Atmospheric Model (NICAM) for global cloud resolving simulations, J. Comput. Phys., 227, 3486-3514, https://doi.org/10.1016/j.jcp.2007.02.006, 2008.

Small, R. J., deSzoeke, S. P., Xie, S. P., O’Neill, L., Seo, H., Song, Q., Cornillon, P., Spall, M., and Minobe, S.: Air-sea interaction over ocean fronts and eddies, Dynam. Atmos. Oceans, 45, 274-319, 2008.

Stephens, G. L.: Radiation profiles in extended water cloud II: Parameterization schemes, J. Atmos. Sci., 35, 2123-2132, 1978.

Stephens, G. L.: Cloud feedbacks in the climate system: a critical review, J. Climate, 18, 237-273, 2005.

Stephens, G. L., Vane, D. G., Boain, R. J., Mace, G. G., Sassen, K., Wang, Z., Illingworth, A. J., O'Connor, E. J., Rossow, W. B., Durden, S. L., Miller, S. D., Austin, R. T., Benedetti, A., Mitrescu, C., and Team TCS: The CloudSat mission and the A-Train, B. Am. Meteorol. Soc., 83, 1771-1790, https://doi.org/10.1175/BAMS-83-12-1771, 2002.

Suzuki, K., Stephens, G. L., van den Heever, S. C., and Nakajima, T. Y.: Diagnosis of the warm rain process in cloudresolving models using joint CloudSat and MODIS observations, J. Atmos. Sci., 68, 2655-2670, 2011. 
Suzuki, K., Stephens, G., Bodas-Salcedo, A., Wang, M., Golaz, J.C., Yokohata, T., and Koshiro, T.: Evaluation of the warm rain formation process in global models with satellite observations, J. Atmos. Sci., 72, 3996-4014, https://doi.org/10.1175/JAS-D-140265.1, 2015.

Tomita, H. and Satoh, M.: A new dynamical framework of nonhydrostatic global model using the icosahedral grid, Fluid Dynam. Res., 34, 357-400, https://doi.org/10.1016/j.fluiddyn.2004.03.003, 2004.

Tsuguti, H. and Kato, T.: Contributing factors of the heavy rainfall event at Amami-Oshima Island, Japan, on 20 October 2010, J. Meteorol. Soc. Jpn., 92, 163-183, https://doi.org/10.2151/jmsj.2014-202, 2014.

Xie, S. P.: Satellite observations of cool ocean-atmosphere interaction, B. Am. Meteorol. Soc., 85, 195-208, 2004.
Xu, H., Xu, M., Xie, S. P., and Wang, Y.: Deep atmospheric response to the spring Kuroshio Current over the East China Sea, J. Climate, 24, 4959-4972, 2011.

Yoshida, Y., Asano, S., Yamamoto, A., Orikasa, N., and Yamazaki, A.: Radiative properties of mid-latitude frontal ice-clouds observed by the shortwave and longwave radiometer-sondes, J. Meteorol. Soc. Jpn., 82, 639-656, https://doi.org/10.2151/jmsj.2004.639, 2004.

Yuter, S. and Houze Jr., R. A.: Three-dimensional kinematic and microphysical evolution of Florida cumulonimbus. Part II: Frequency distributions of vertical velocity, reflectivity, and differential reflectivity, Mon. Weather Rev., 123, 1941-1963, 1995. 